\title{
A perforated gastrovascular cavity in the symbiotic deep-water coral Leptoseris fragilis: a new strategy to optimize heterotrophic nutrition*
}

\author{
Dietrich Schlichter \\ Zoologisches Institut der Universität Köln; Weyertal 119, D-W-5000 Köln 41, \\ Federal Republic of Germany
}

\begin{abstract}
The organization of the zooxanthellate scleractinian coral Leptoseris fragilis was studied. The architecture of the corallite and the histology of the polyparium were analysed for adaptations that enable efficient capture and retention of suspended particles which would increase energy supply. The data indicate that the gastrovascular system of $L$. fragilis is not a blind but a flowthrough system. Water entering the coelenteron through the mouth leaves the body not only through the mouth but also through microscopic pores $(\varnothing 1-2 \mu \mathrm{m})$ which are located near the crests of the sclerosepta in the oral epithelia. Irrigation is achieved by flagellar and probably also by muscular activity. This type of filtration enables $L$. fragilis, which lacks tentacles, to utilize suspended organic material including bacteria. The supposed suspension feeding in combination with effective photoadaptations (presented in former communications) seems to be the basis for the survival of $L$. fragilis in an extreme habitat (between -95 and $-145 \mathrm{~m}$ ) and for its, successful competion with other scleractinian species provided with larger catching surfaces, and with other invertebrates depending on filter feeding.
\end{abstract}

\section{INTRODUCTION}

The bathymetric distribution of Leptoseris fragilis (Milne Edwards \& Haime) between -95 and $-145 \mathrm{~m}$ (maximum) is extraordinary for a zooxanthellate scleractinian coral species (Fricke $\&$ Schuhmacher, 1983). Therefore, the photoadaptations responsible for the outstanding photosynthetic capacity have been studied (Schlichter et al., 1985, 1986, 1988; Fricke et al., 1987, 1991; Schlichter \& Fricke, 1990, 1991). In situ studies of photosynthesis revealed two important results: (a) The photokinetic parameters determined for $L$. fragilis are the lowest ever reported for symbiotic cnidarian species; i.e. L. fragilis stands out for its efficient utilization of low photon flux densities of particular spectral composition; (b) Calculations of energy budgets - based on 24-h in situ measurements - showed that metabolism can be maintained by autotrophy (phototrophy) only during summer, while during months with low solar elevation the combined metabolism of host and symbionts needs additional heterotrophic fueling (Fricke et al., 1987, 1991). Other strategies to compensate reduced phototrophy could be the reduction of metabolism for several months and/or the utilization of storage products.

Heterotrophic feeding habits of the coral host include (a) the absorption of dissolved

- Dedicated to W. Weber 1923-1987

(c) Biologische Anstalt Helgoland, Hamburg 
organic material (DOM; carbohydrates, amino acids, fatty acids) and (b) the utilization of particulate organic material (POM; detritus, bacteria, plankton) (Sebens, 1987).

The apparent necessity of supporting the combined metabolism of host and symbionts. - at least temporarily - by heterotrophic means prompted research on the structural basis for effective POM feeding. Especially intriguing are the facts that $L$. fragilis lacks tentacles and that this species grows in a habitat far from the more productive levels near the surface. In addition, $L$. fragilis lives in competition with motile and sessile invertebrate species including, for example, azooxanthellate scleractinians which appear to be far better adapted to capturing POM, as they are equipped with tentacles - thus enlarging the catching surface - and have far more nematocysts.

Analysing the organization of $L$. fragilis is not only interesting from an adaptive point of view - improvement of capturing efficiency - but also from a comparative aspect: the discoidal organization of $L$. fragilis differs from the general features of madreporarian species (Chevalier, 1987; Hoeksema, 1989; Le Tissier, 1990).

\section{MATERIALS AND METHODS}

Specimens of Leptoseris fragilis and Dendrophyllia minuscula (Bourne) were collected with the research submersible GEO at depths between -100 and $-135 \mathrm{~m}$ in front of the Heinz Steinitz Marine Biology Laboratory at Eilat, Gulf of Aqaba, Red Sea. The corals were detached with a chisel and subsequently transferred into incubation chambers, which were mounted on a platform below the front dome of the submersible. The chambers $(273-276 \mathrm{ml})$ were closed and the specimens remained undisturbed for about $15 \mathrm{~min}$. Then glutardialdehyde was injected into the chambers giving a final concentration of $4 \%$. Mixing was performed with a magnetic stirring bar. The preserved specimens were brought to the surface. On board a supporting vessel, small pieces were cut off from the skeletons and were subsequently post-fixed in $2 \%$ osmium tetroxide for $2 \mathrm{~h}$ at ambient temperature. Specimen of Goniopora planulata (Ehrenberg) originating from shallow water were preserved in the laboratory in the same way.

Electron microscopy was performed according to standard laboratory methods. Material for transmission electron microscopy was treated and embedded after the double procedure of Pilkington (1969). The dehydrated pieces were embedded in Spurrresin (Spurr, 1969). For decalcification, the plastic material was removed from the embedded pieces until the skeletons appeared on the surface. The small cubes were treated for several hours with $4 \%$ acetic acid under vacuum. After rinsing and drying, the demineralized pieces were reembedded in Spurr-resin.

\section{RESULTS}

General remarks on the corallite and the polyparium of Leptoseris fragilis

Skeletons of the plate-shaped coral $L$. fragilis attain a diameter of up to $8 \mathrm{~cm}$ (Fig. 1a). The corallite is thin and fragile. The gross morphology is fundamentally in accordance with the basal plate of a just metamorphosed coral planula. The calyx (axial hole) is laterally compressed to a slender oval cylinder. The central axial edges of the sclerosepta - forming the contour of the axial hole - tower above the other parts of the 

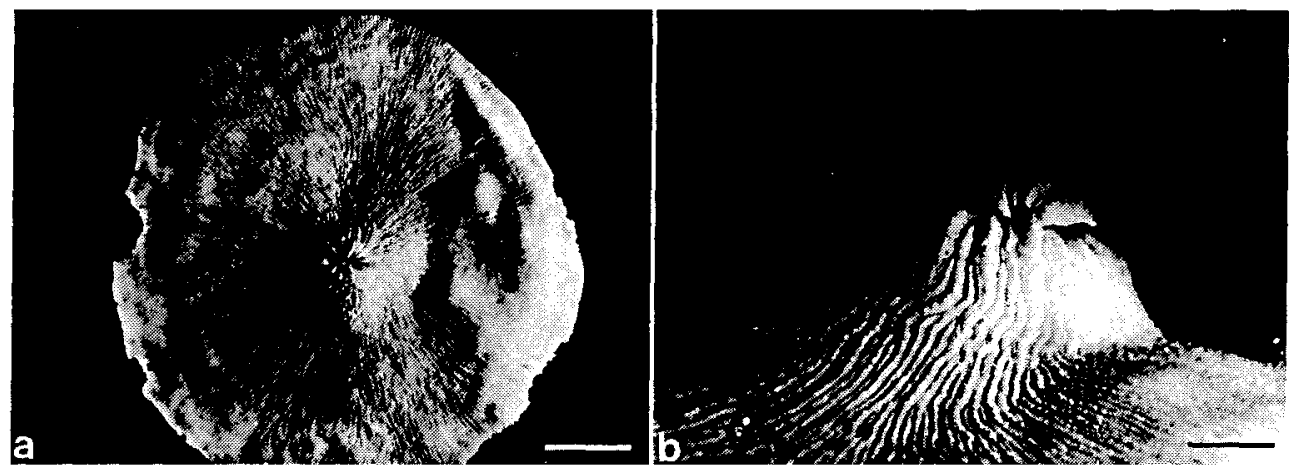

Fig. 1. Skeleton of the symbiotic deep water coral Leptoseris fragilis. a: Surface view; b: Profile of the oral area. Scale bars: a: $10 \mathrm{~mm}$; b: $3 \mathrm{~mm}$

skeleton like the walls of a crater (Fig. 1b). The columella is composed of fused papillae producing a meandrine structure which shows periodic growth accretions. Frequently, the skeletons are attached to the substrate by carbonate depositions which form rib-like walls between the aboral side of the skeletons and the bottom (Fig. 4a). The skeleton is covered by thin epithelia $(20-40 \mu \mathrm{m})$. However, the underside of the skeleton is more or less free of tissue and almost totally covered by epibionts.

The surface of living specimens shows a regular pattern of alternating dark and pale stripes. The pattern corresponds to the distal and proximal parts of the sclerosepta (crests and grooves). The colour pattern results from the distribution of zooxanthellae and chromatophores. In situ living specimens appear dark brownish, almost black. The rim of the disc appears whitish, i. e. zooxanthellae are absent, indicating that areas of fastest linear growth are without symbionts.

The surface of living specimens sometimes showed greyish plaques (bacteria, fungi). Along the external parts of the sclerosepta, short, coiled portions of filaments could be observed $_{i}$ the filaments were squeezed out due to tissue damage during handling.

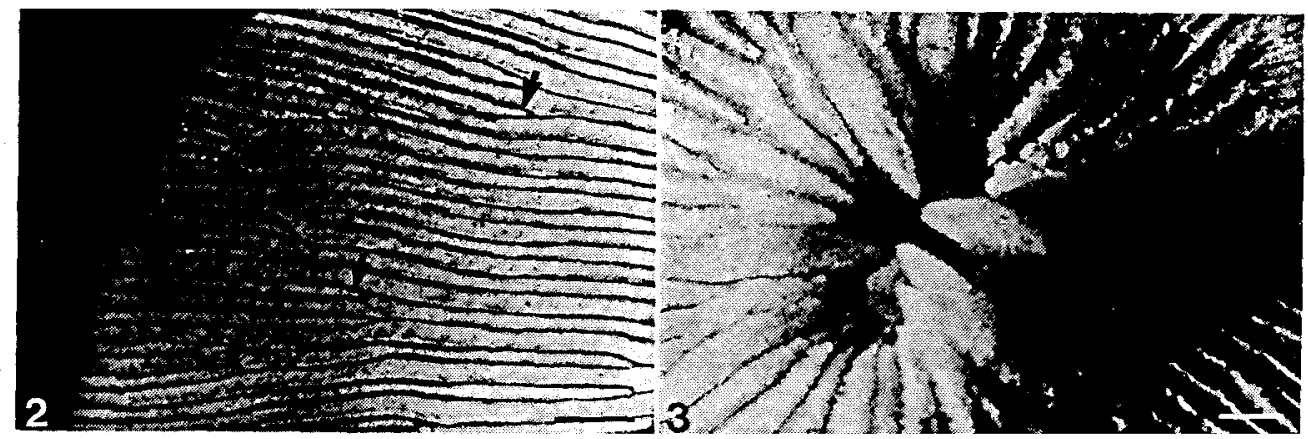

Fig 2. A sector of the oral skeleton surface of Leptoseris fragilis. The insertion of new sclerosepta is marked by arrows. Scale bar: $1 \mathrm{~mm}$

Fig. 3. View into the axial hole of Leptoseris fragilis. Principal sclerosepta are conspicuous in size. The columella is visible at the bottom of the calyx. Scale bar: $1 \mathrm{~mm}$ 
The skeleton

In $L$. fragilis the vertical body axis is compressed, producing its typical discoidal shape. The slit-like calyx adds to the bilateral symmetry of the body (Figs 1a, 3, 17a, b). The sclerosepta radiate from the centre. Towards the periphery, younger sclerosepta are inserted (Fig. 2). The border of the calyx is composed of up to 30 sclerosepta, 6 or 12 of which are conspicuous in size (Fig. 3). The sclerosepta are solid in their central axial parts

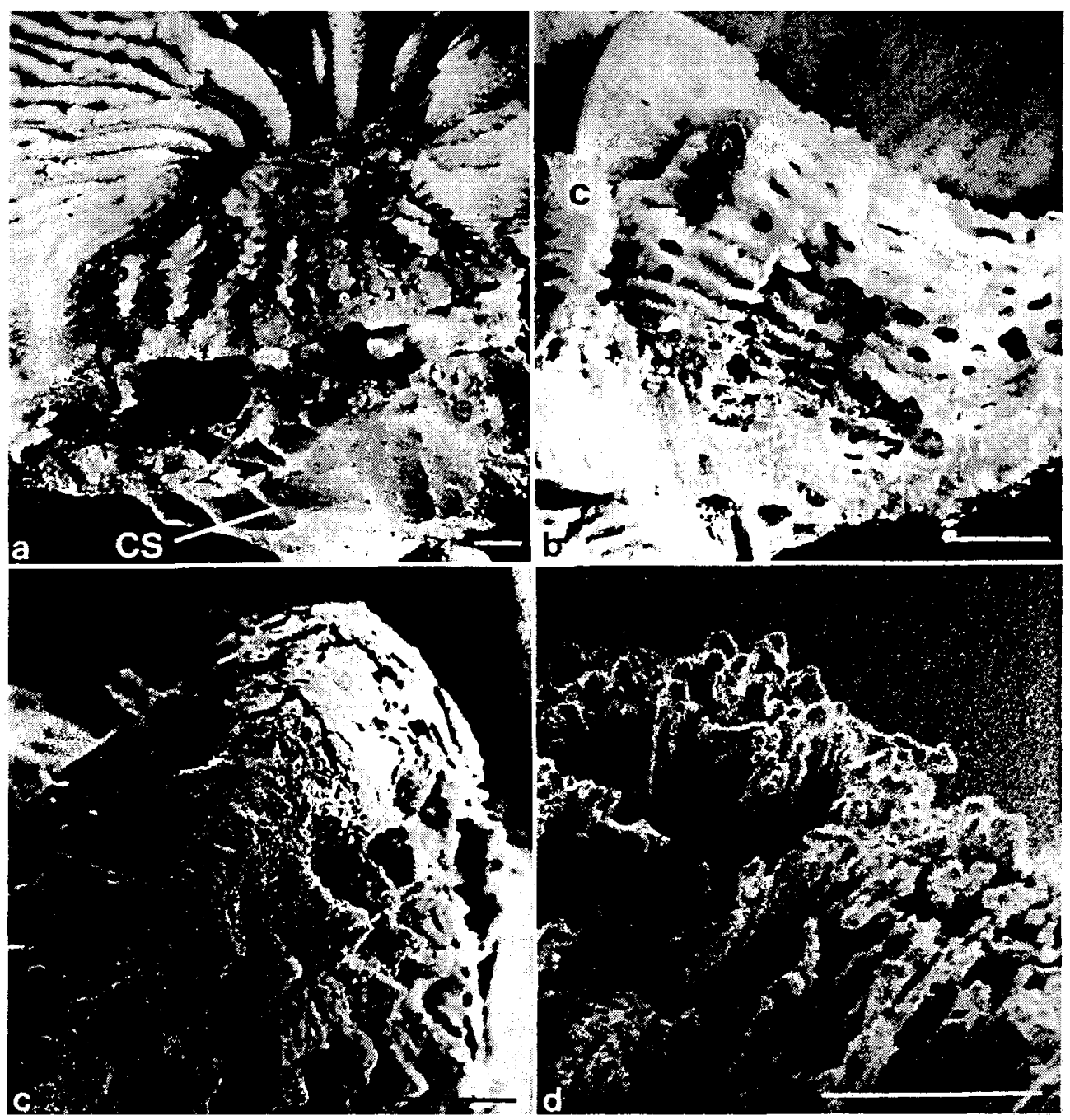

Fig. 4. a: Vertical section through the calyx of a skeleton of Leptoseris fragilis. Below the corallite proper, structures are visible cementing the corallite to the ground. Scale bar: $1 \mathrm{~mm}$. b: The central part of the corallite displays perforated sclerosepta and fused lateral lamella of the sclerosepta. Scale bar: $1 \mathrm{~mm}$. c: Denticulated surface of the sclerosepta. Scale bar; $200 \mu \mathrm{m}$. d: Carbonate deposition in the form of needles. Scale bar: $3 \mu \mathrm{m}$. Abbreviations: $\mathrm{C}=$ columella, $\mathrm{CS}=$ cavern system, arrow $=$ 
bordering the calyx, and the surface is dentated or nodulated. Distal to the calyx the solid region is followed by a portion which is perforated (Fig. $4 \mathrm{~b}$ ), but towards the periphery the sclerosepta are again solid. In the central part of the corallite the perforated portions of the sclerosepta produce a filigree lattice-work. The sclerosepta show an interesting microarchitecture. The flanks and especially the crests are dentated (Fig. 4c). The flanks of the sclerosepta are sculptured along their horizontal, longitudinal axis into lamella which form a system of ducts (Figs $5 a, b ; 6 a, b ; 8 a, b$ ). The number of gastric ducts of each scleroseptum decreases from the centre towards the periphery because the height of septa decreases (Fig. 5a).

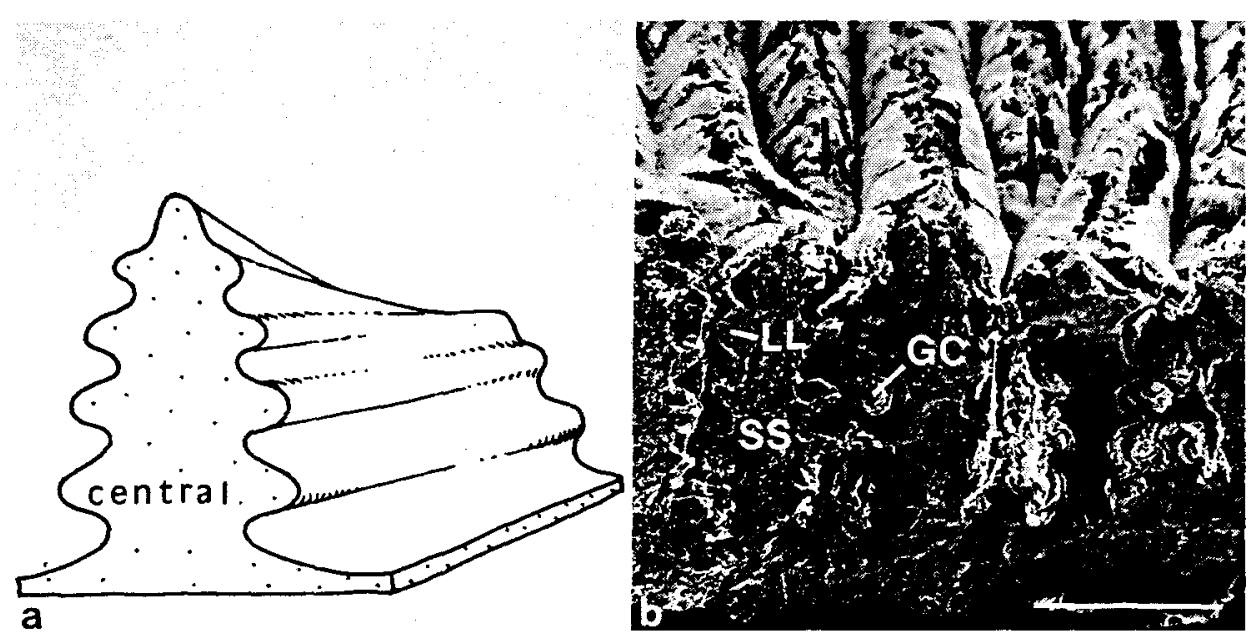

Fig. 5. a: Diagram of a part of a scleroseptum. The decrease of lateral lamella from the centre of the skeleton towards the periphery is shown. The details are not drawn to scale and perforations and surface structures were omitted. b: Fracture of adjacent sclerosepta. The callicoblastic epidermis is detached from the corallite. Some of the gastric ducts encircled by the lateral lamellae are packed with debris while others are not. The arrows indicate the insertion of subsidiary sclerosepta.

Abbreviations: $\mathrm{SS}=$ scleroseptum, $\mathrm{LL}=$ lateral lamella, $\mathrm{GC}=$ gastric duct. Scale bar: $430 \mu \mathrm{m}$

In the upper regions, the sclerosepta grow vertically and produce new lamella laterally, whereas in the lower regions the gastric ducts lose their function due to the fusion of adjacent lamellae (forming dissepiments) leading to a complete separation of the lower from the upper ducts (Fig. $6 a, b$ ). This mechanism is the basis for vertical growth of the skeleton. The free lamellae of adjacent sclerosepta stand in zigzag geometry (zip-like) which may have functional consequences (see "Discussion"). Circular depressions in the skeleton, at which points the living callicoblastic ectoderm (= aboral epidermis) is attached to the corallite, are abundant. At the back of the corallite, costal structures are only weakly developed.

The skeletons are frequently invaded by filamentous algae which stain the corallite green and/or brown-beige. The algal filaments grow along the tissue/skeleton interface (Fig. $7 \mathrm{a}, \mathrm{b}$ ). This makes parasitic or mutualistic metabolic interactions likely. Of particular interest is the observation that the endolithic algae alter the cristalline structure of the sclerosepta (Figs 5b, 6b). 

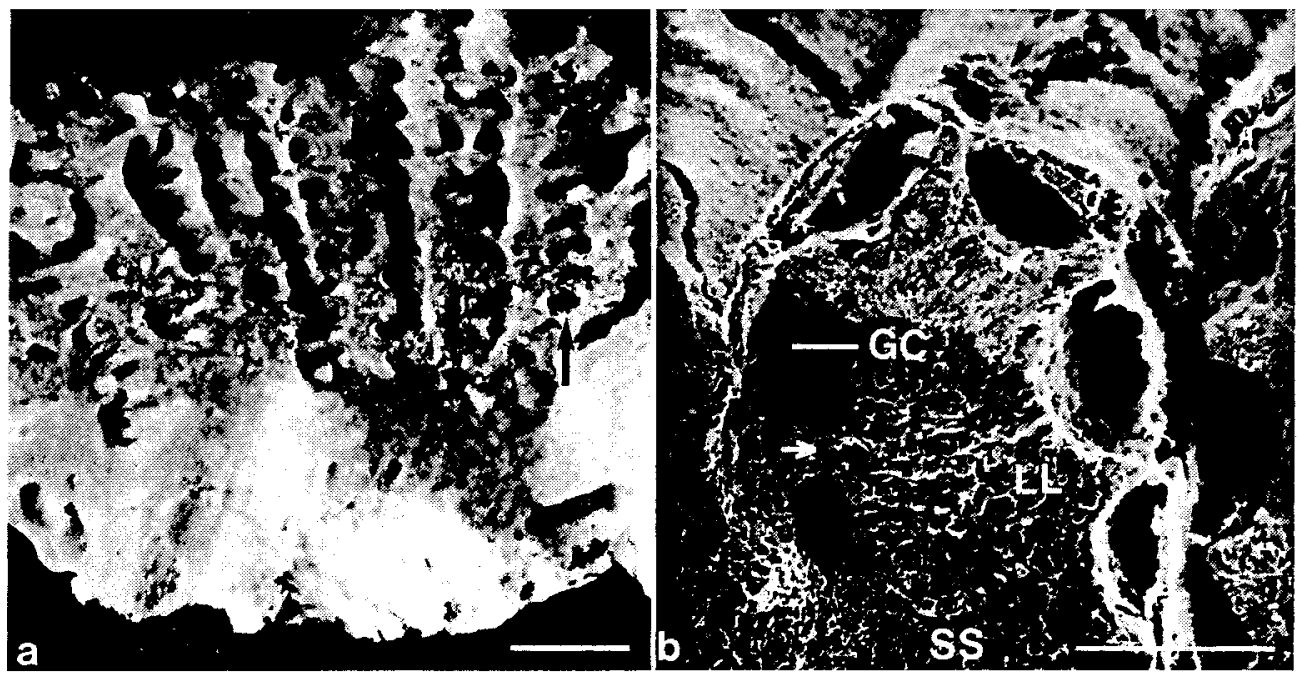

Fig. 6. a: Lateral lamella of adjacent sclerosepta may fuse (arrows) and the gastric ducts lose their function, as indicated by the absence of tissue; b: In the central region of the scleroseptum the crystalline structure is altered, due to activities of endolithic algae (see Figs $5 b, 7 a, b, 16 a$ ). Abbreviations: $\mathrm{SS}=$ scleroseptum, $\mathrm{LL}=$ lateral lamella, $\mathrm{GC}=$ gastric duct. Scale bars: $\mathrm{a}: 1 \mathrm{~mm} ; \mathrm{b}: 150 \mu \mathrm{m}$

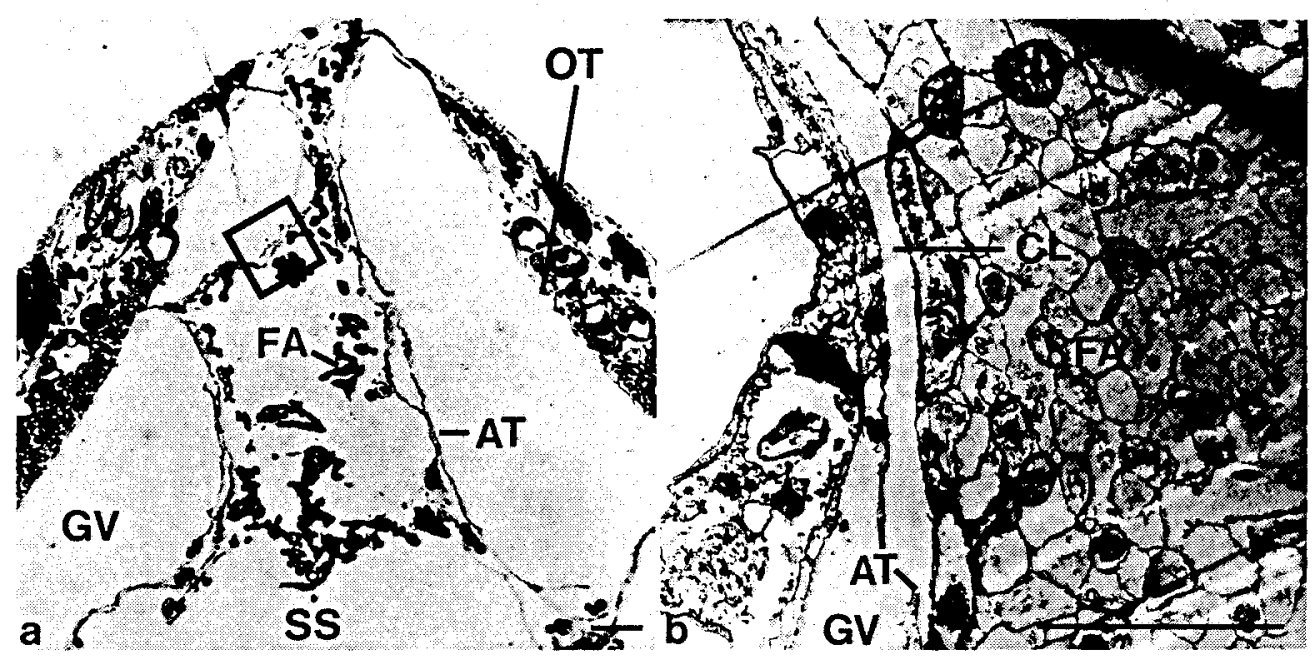

Fig. 7. Skeleton of Leptoseris fragilis invaded by filamentous algae (sections from decalcified samples; for orientation see insert 1 in Fig. 8a). a: Survey; b: The interface between callicoblastic epidermis and filamentous algae living within the sclerosepta. For orientation see insert in Figure $7 a$. Abbreviations: $\mathrm{OT}=$ oral epidermis and gastrodermis, $\mathrm{AT}=$ aboral epidermis and gastrodermis, $\mathrm{FA}=$ filamentous algae, $\mathrm{GV}=$ gastrovascular system, $\mathrm{SS}=$ scleroseptum, $\mathrm{CL}=$ cleft (callicoblastic epidermis detached from corallite). Scale bars: a: $10 \mu \mathrm{m} ; \mathrm{b}: 10 \mu \mathrm{m}$ 


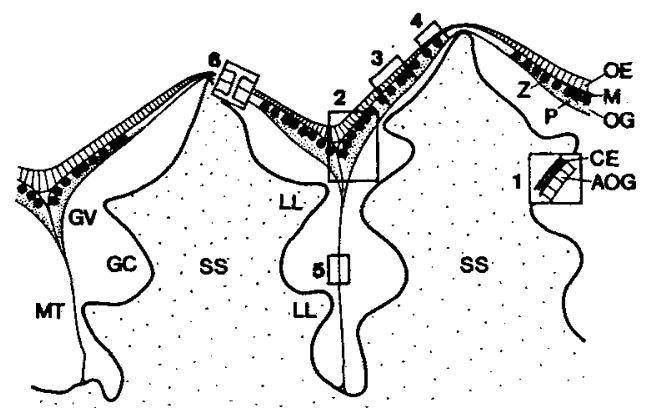

a

Skeleton

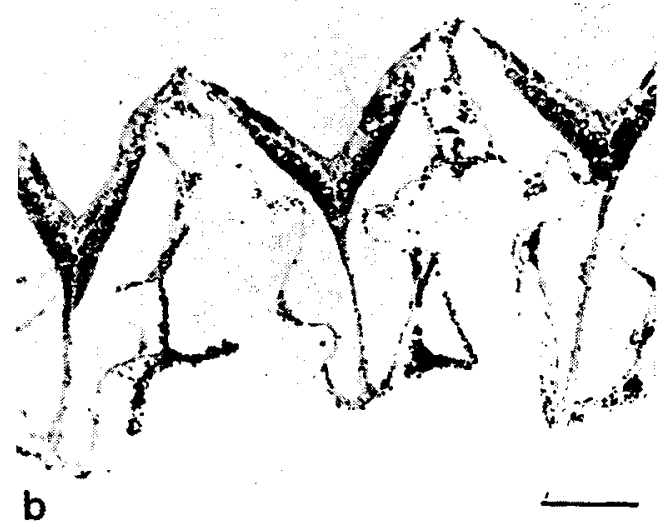

Fig. 8. a: Diagram of a section of two adjacent sclerosepta covered with the polyparium. The oral tissues are stretched tentlike between the sclerosepta. Gastrovascular pockets, lined by mesenteries, are divided by one scleroseptum into two compartments and these are further subdivided into gastric ducts by lateral lamella of the sclerosepta. The numbered insertions are referred to in subsequent figures of this paper. b: Section of a decalcified specimen. Abbreviations: $O E=$ oral epidermis, $\mathrm{M}=$ mesogloea, $\mathrm{OG}=$ oral gastrodermis, $\mathrm{Z}=$ zooxanthellae, $\mathrm{P}=$ pigment granules, $\mathrm{CE}=$ callicoblastic epidermis, $\mathrm{AOG}=$ aboral gastrodermis, $\mathrm{GV}=$ gastrovascular system, $\mathrm{GC}=$ gastric duct, $\mathrm{SS}=$ scleroseptum, $\mathrm{LL}=$ lateral lamella, $\mathrm{MT}=$ mesentery. Scale bar: $100 \mu \mathrm{m}$

\section{The tissues of the polyparium}

In the following sections, the histology of the polyparium of $L$. fragilis is described in detail. The schematic drawing of a vertical cross-section through the skeleton and the overlying tissues depicts the microscopical anatomy (Fig. 8a).

The aboral epithelia. The callicoblastic epidermis (= aboral ectoderm) and the aboral gastrodermis (= aboral endoderm) are thin, both layers ranging between 0.5 and $2 \mu \mathrm{m}$ in thickness, i.e. the aboral epithelial cells are extremely compressed. The mesogloea (mesolamella) between the two cell layers seems to be totally reduced. The aboral gastrodermis is equipped with few flagella, and zooxanthellae are absent (Fig. 9).

The oral epidermis (= oral ectoderm) consists mainly of a spongy layer of cells whose external (apical) membrane is provided with microvilli, macrovilli and 


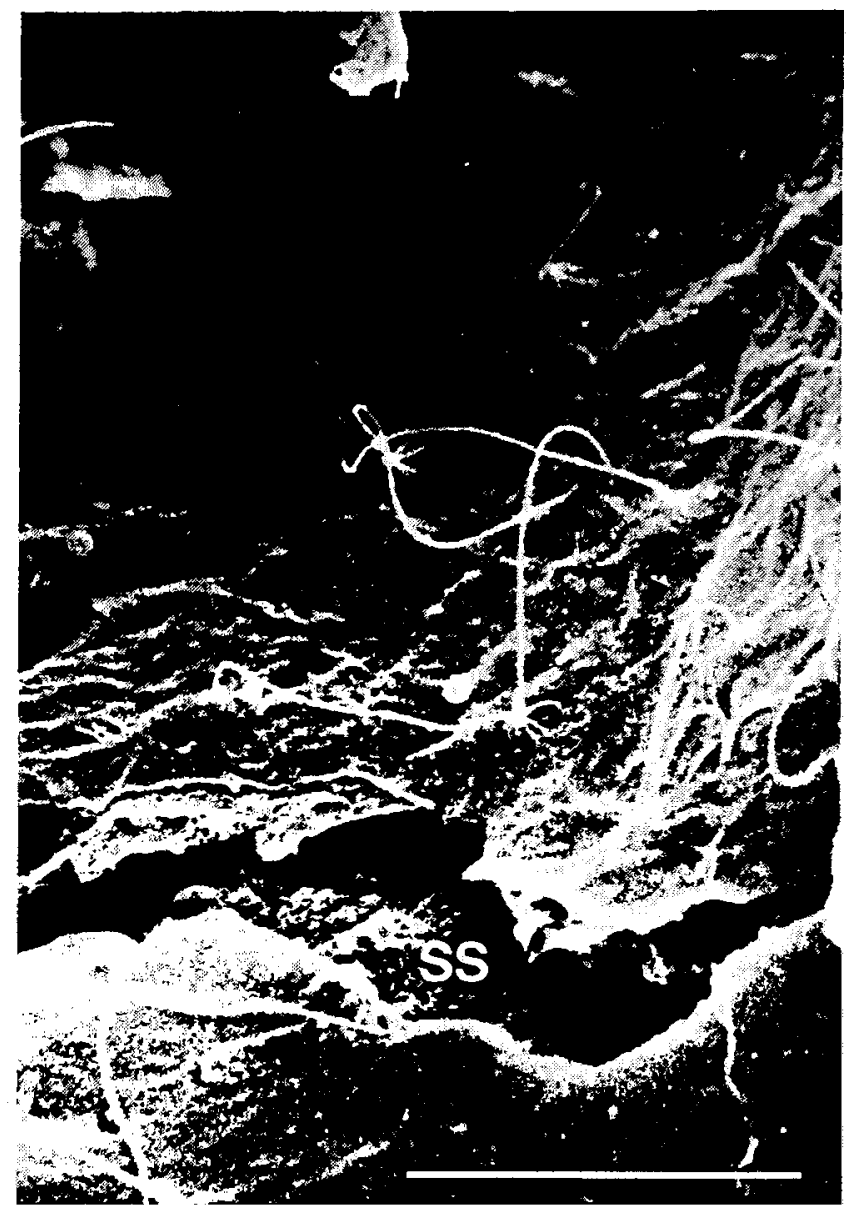

Fig. 9. View of the aboral gastrodermis (insert 1 in Fig. 8a). The aboral tissues are extremely thin. The surface is sparsely covered with flagella (compare with Fig. 14). SS = scleroseptum. Scale bar: 30 um

numerous flagella, prerequisites for suspension feeding (Fig. 10c, d). The flagella have accessory structures around their base. Towards their base, the epithelio-muscular cells taper into columnar processes containing the nucleus, and terminate in contact with the mesogloea. The large intercellular spaces (Fig. 10a, b) may facilitate the penetration of light to the zooxanthellae and to the chromatophores. Further cell types which can be sporadically identified are mucous cells and functional nematocysts (Fig. 11a, b). The nematocysts are found in groups around large secretory cells. The stinging batteries are located on or near the top of the sclerosepta. In Figure 13, a glandular cell is shown, indicating the synthesis of secretory granules by the Golgi apparatus.

The oral gastrodermis (= oral endoderm) consists of a layer of columnar cells, harbouring zooxanthellae (12 $\mu \mathrm{m}$ in diameter in maximum) (Figs 9, 10, 12). Each host cell contains only one symbiont (Fig. 12). The host cells containing the algae are 

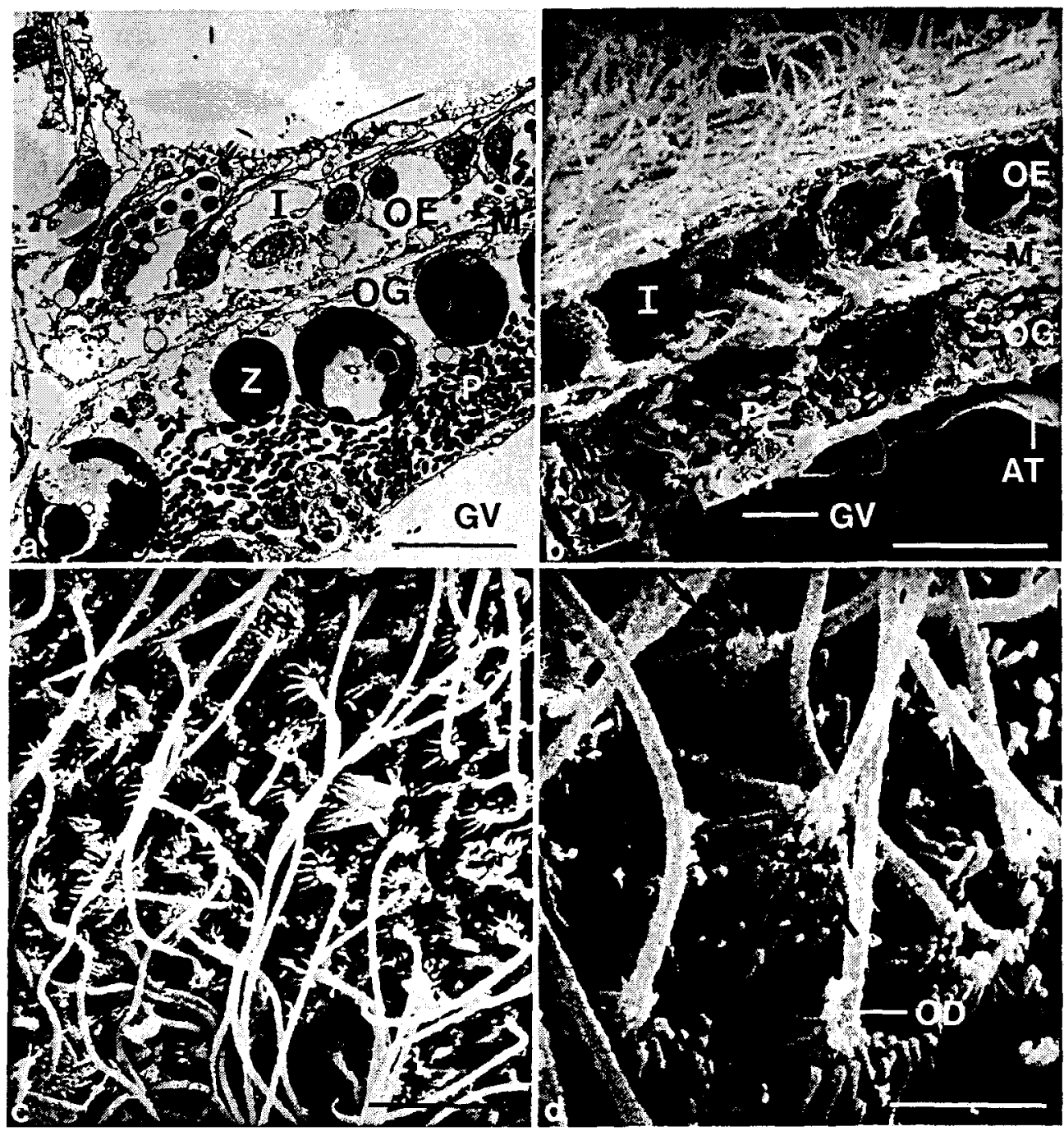

Fig. 10. The histological organization of the oral epithelia. For orientation see inserts 2 and 3 in Fig. 8a. a: The oral epidermis is of spongy consistency and the mesogloea is weakly developed. The oral gastrodermis is prominent and harbours zooxanthellae. b: The oral epidermis shows large intercellular spaces. The oral gastrodermis displays conspicuous, dense accumulations of pigment granules (see also Fig. 12). During preservation the aboral epithelia became detached from the skeleton. $c$, d: The flagella of the oral epidermis are provided with accessory structures at the base of which two types exist (arrows). Abbreviations: $O E=$ oral epidermis, $I=$ intercellular space, $M=$ mesogloea, $\mathrm{OG}=$ oral gastrodermis, $\mathrm{Z}=$ zooxanthellae, $\mathrm{P}=$ pigment granules, $\mathrm{AT}=$ aboral epidermis and gastrodermis, $G V=$ gastrovascular system, $O D=$ organic debris. Scale bars: a: $10 \mu m_{i}$ b: $12 \mu m_{\text {; }}$ c: $5 \mu \mathrm{m} ; \mathrm{d}: 2 \mu \mathrm{m}$ 


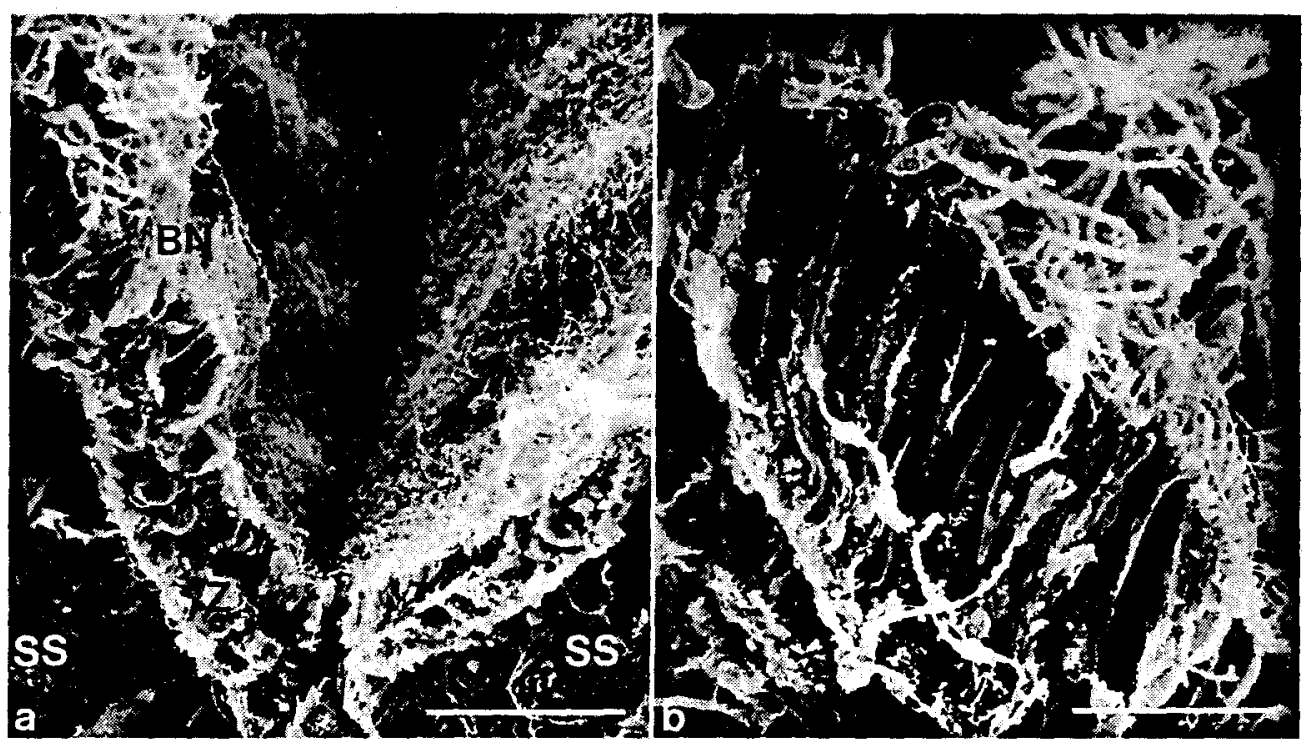

Fig. 11. Stinging batteries are localized in the upper regions of the sclerosepta or near the top (insert 4 in Fig. 8a). a: Survey; b: detail. Abbreviations: $\mathrm{BN}=$ battery of nematocysts, $\mathrm{SS}=$ scleroseptum, $\mathrm{Z}=$ zooxanthellae. Scale bars: a: $50 \mu \mathrm{m} ; \mathrm{b}: 20 \mu \mathrm{m}$

largely reduced which might indicate particular metabolic conditions. The zooxanthellae lie predominantly in one plane thus avoiding self-shading (Fig. 10a). The intercellular spaces between the cells harbouring the algae are filled by ramifications of chromatophore cells. The ramifications are densely packed with granules which contain autofluorescent pigments transforming short wavelengths into longer ones. The pigment granules form a continuous stratum underlying and partially covering the zooxanthellae (Schlichter et al., 1985, 1986). The oral gastrodermis, in contrast to the aboral gastrodermis, is equipped with a high density of flagella (Fig. 14). The absence of a gastrodermal brushborder may indicate the uptake of POM by endocytosis. A weakly developed mesogloea is present. Contractile, neuroide and sensory structures are rarely observed.

The oral epithelia of $L$. fragilis and of two colonial scleractinian coral species were compared: (a) the zooxanthellate species Goniopora planulata, originating from shallow waters, and (b) Dendrophyllia minuscula, without zooxanthellae, collected at $-127 \mathrm{~m}$ depth. The two symbiotic species show - with the exception of the chromatophore system - strong histological similarities (compare Figs 10a and 15a). In both, the oral epidermis is poorly developed, few nematocysts are present and the gastrodermis with zooxanthellae is three times thicker than the epidermis. In the azooxanthellate deep water species, the

Fig. 13. Formation of secretory granules in the oral epidermis. Abbreviations: $\mathrm{SG}=$ secretion granules, $\mathrm{GA}=$ Golgi apparatus. Scale bar: $5 \mu \mathrm{m}$

Fig. 14. Surface view of the oral gastrodermis (insertions 2, 3 in Fig. 8a), densely covered with flagella in contrast to the aboral gastrodermis (see Fig. 9). Scale bar: $20 \mu \mathrm{m}$ 


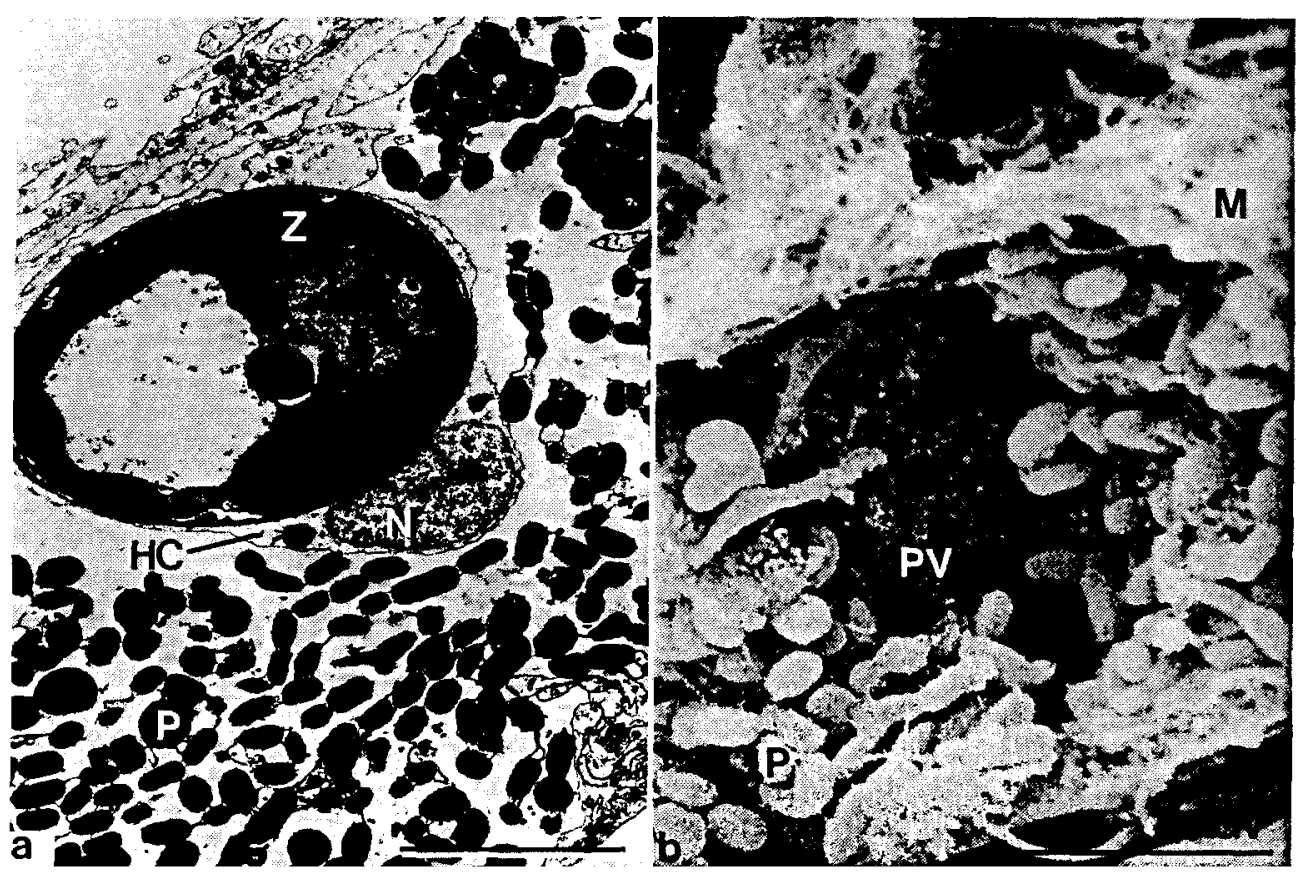

Fig. 12. Zooxanthellae are found exclusively in the oral gastrodermis of Leptoseris fragilis (insertions 2 and 3 in Fig. 8a). a: Each gastrodermal cell contains only one cytosymbiont. b: The zooxanthellae are surrounded by numerous pigment granules belonging to a chromatophore system of the host (see Fig. 10a, b). Abbreviations: $\mathrm{Z}=$ zooxanthellae, $\mathrm{HC}=$ host cell, $\mathrm{P}=$ pigment granules, $\mathrm{M}=$ mesogloea, $\mathrm{PV}=$ perialgal vacuole, $\mathrm{GV}=$ gastrovascular system, $\mathrm{N}=$ nucleus. Scale bars: a: $5 \mu \mathrm{m}$;

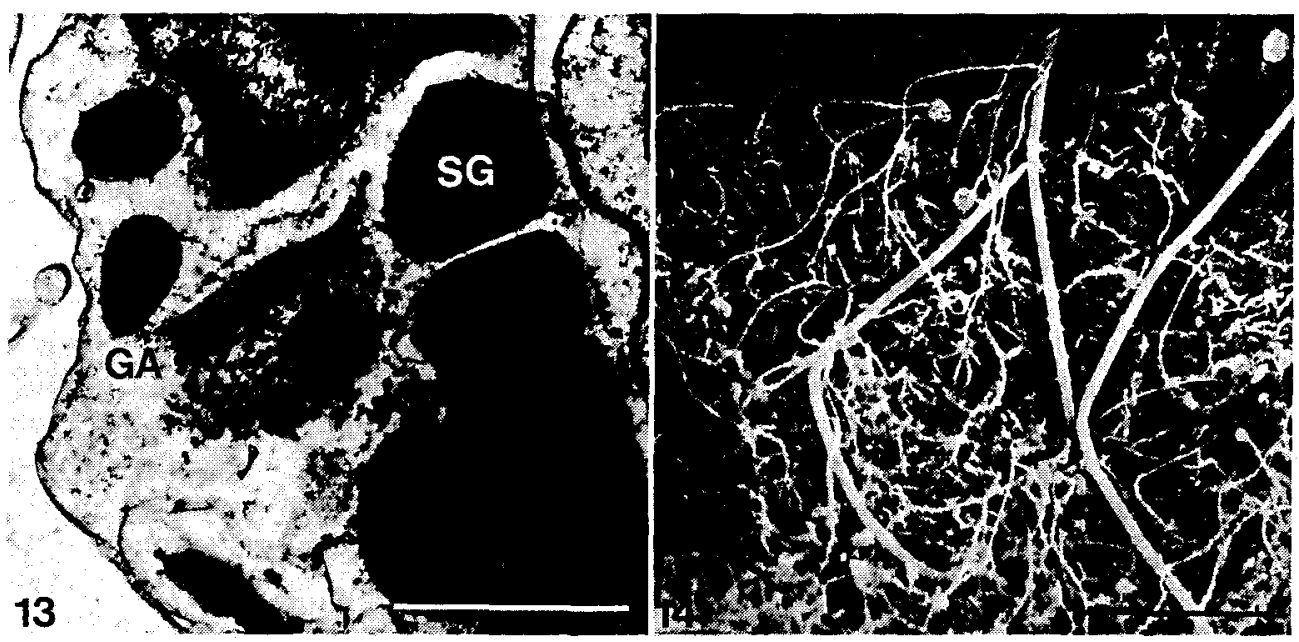




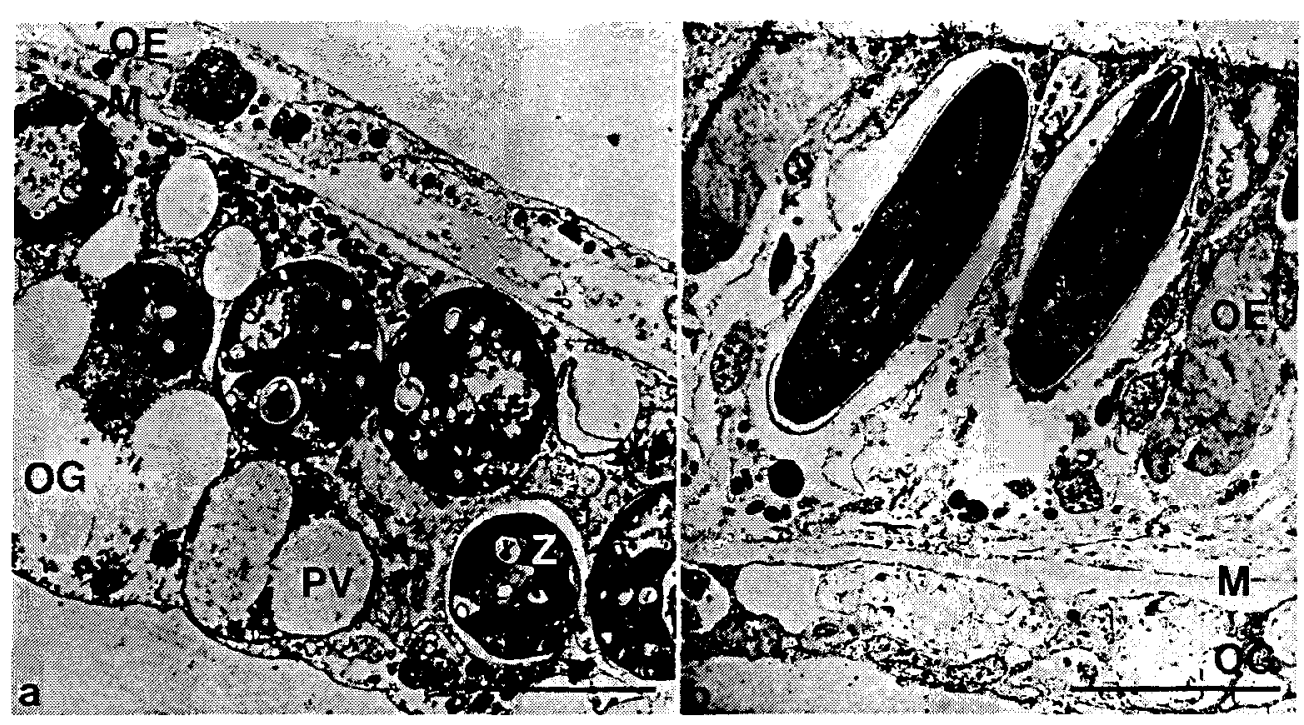

Fig. 15. Comparison of the oral tissue layers of zooxanthellate and an azooxanthellate scleractinian coral species. a: In Goniopora planulata, containing symbionts, as also in L. fragilis, the algaecontaining gastrodermis predominates (see Fig. 10a). b: In Dendrophyllia minuscula, without zooxanthellae, the oral epidermis predominates. Abbreviations: $O E=$ oral epidermis, $M=$ mesogloea, $\mathrm{OG}=$ oral gastrodermis, $\mathrm{Z}=$ zooxanthellae, $\mathrm{PV}=$ perialgal vacuole, $\mathrm{NE}=$ nematocysts. Scale bars: $10 \mu \mathrm{m}$

epidermis is prominent and nematocysts and glandular cells are frequent (Fig. 15b). The gastrodermis is weakly developed and about a quarter as thick as the epidermis.

\section{The organization of the gastrovascular system}

The aboral epithelia (gastrodermis and epidermis) cover the corallite. The oral epithelia (also gastrodermis and epidermis) stretch tent-like from one scleroseptum to the next (Figs $5 b ; 8 a, b ; 16 a$ ). The oral epidermis thus forms an undulating coat dropping inwards slightly between the sclerosepta (Figs $8 a, b ; 16 a$ ). In contrast, the oral gastrodermis reaches down between the sclerosepta and fuses with the aboral gastrodermis. Each gastrovascular pocket, laterally defined by mesenteries, is divided into two subunits by a scleroseptum (Fig. 8a, b). The gastrovascular pockets communicate along the crests of the sclerosepta and in the central area of the corallite through the scleroseptal perforations (Fig. 4 b).

The gastrovascular pockets, divided into two smaller chambers by sclerosepta, are further subdivided into radial gastric ducts by the lateral lamellae on the flanks of the sclerosepta (Figs 5, 6). The number of functioning ducts stacked upon each other differs, reaching more than 7 in the centre (Fig. 5). Fractures show that only those ducts which are not yet completely closed are lined with living tissue (Fig. 6b). On the periphery, the number of ducts declines to two (Figs $5 \mathrm{a}, 6 \mathrm{~b}$ ). In the mesenteries, consisting of a central mesogloea and two gastrodermal cell layers, contractile elements are present. The contractile filaments of epithelio-muscular cells run vertically forming retractor muscles. 

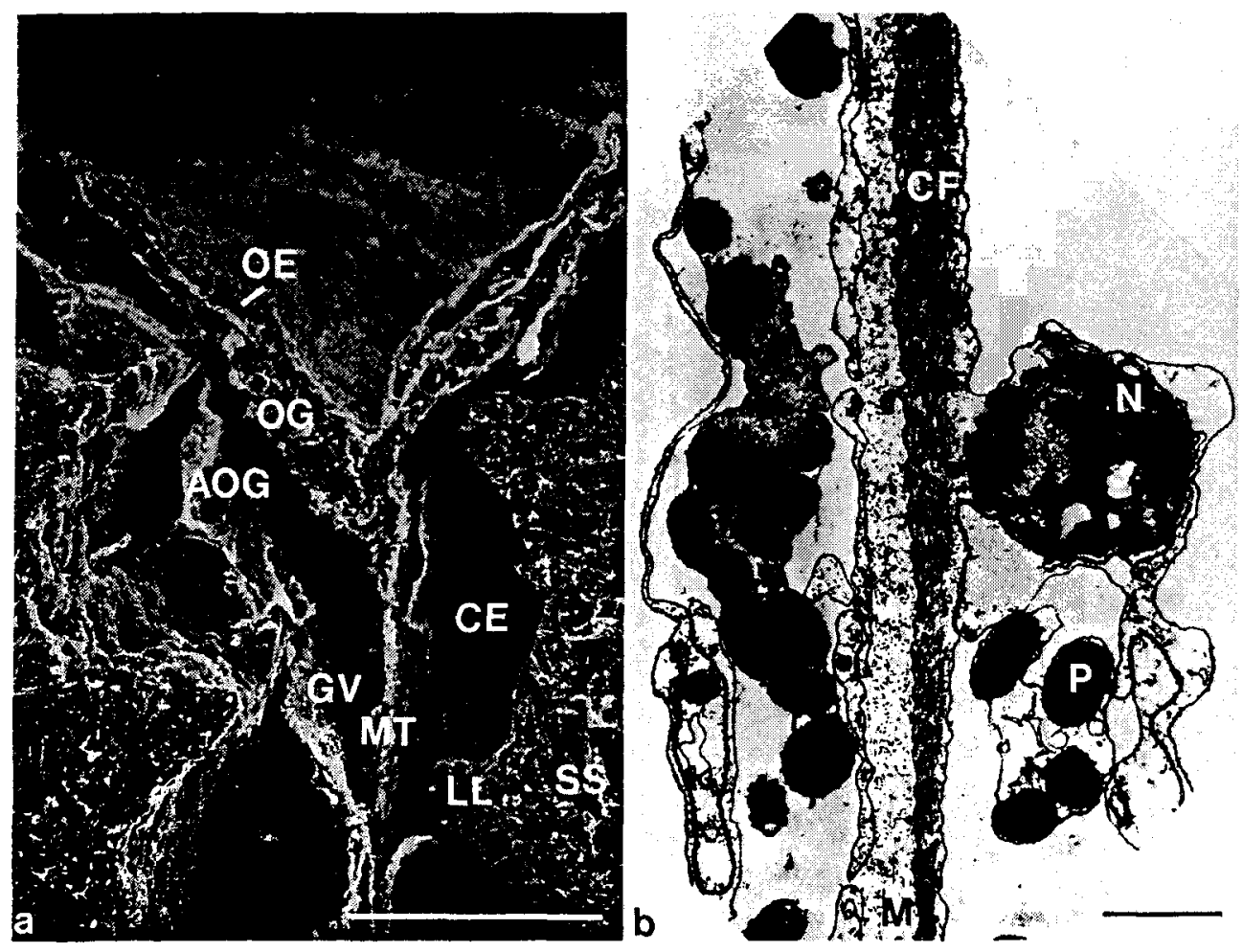

Fig. 16. The organization of the gastrovascular system in the periphery of the corallite. a: Section through adjacent sclerosepta covered with the polyparium. Due to detachment of the epithelia the natural topography is somewhat disturbed (see insertions 2-4 in Fig. 8a). b: Longitudinal section through a mesentery (see insertion 5 in Fig. 8a). The nucleus of the epithelio-muscular cell is located excentrically. The myofibrilar components are anchored within the mesogloea. Abbreviations: $O E=$ oral epidermis, $O G=$ oral gastrodermis, $A O G=$ aboral gastrodermis, $G V=$ gastrovascular system, $\mathrm{MT}=$ mesentery, $\mathrm{CE}=$ apical membrane of the callicoblastic epidermis (detached from the corralite), $\mathrm{LL}=$ lateral lamella, $\mathrm{SS}=$ scleroseptum, $\mathrm{CF}=$ contractile filaments, $\mathrm{M}=$ mesogloea, $\mathrm{N}=$ nucleus, $\mathrm{P}=$ pigment granules. Scale bars: $\mathrm{a}: 100 \mu \mathrm{m} ; \mathrm{b}: 1 \mu \mathrm{m}$

The myofibriliar components of the epithelio-muscular cells are anchored in the mesogloea (Fig. 16b).

\section{The oral area (peristome and stomodaeum)}

The slit-like stomodaeum is located in the laterally compressed calyx bordered by the axial edges of the sclerosepta (Figs $3,17 a, b$ ). The mouth has a circular appearance and may work like an iris diaphragm.

The pharynx is densely covered with flagella (Fig. 18a, b). From the pharynx the gastric ducts radiate outwards to the periphery perpendicularly; a central gastral cavity is lacking (Figs 4, 17, 18a). 


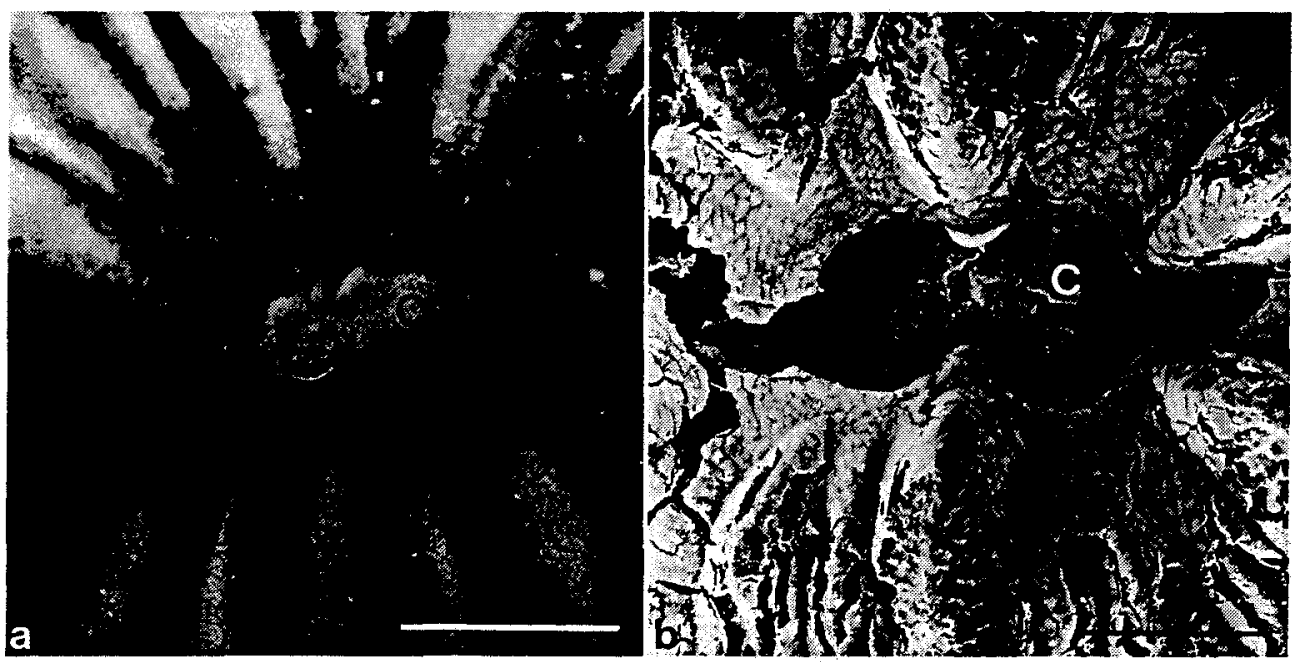

Fig. 17a, b: Leptoseris fragilis. View into the central stomodaeum and pharynx (preserved specimens). At the bottom of the gastrovascular system the columella is visible. Abbreviations: $\mathrm{S}=$ stomodaeus, $\mathrm{C}=$ columella. Scale bars: $\mathrm{a}: 1 \mathrm{~mm} ; \mathrm{b}: 1 \mathrm{~mm}$

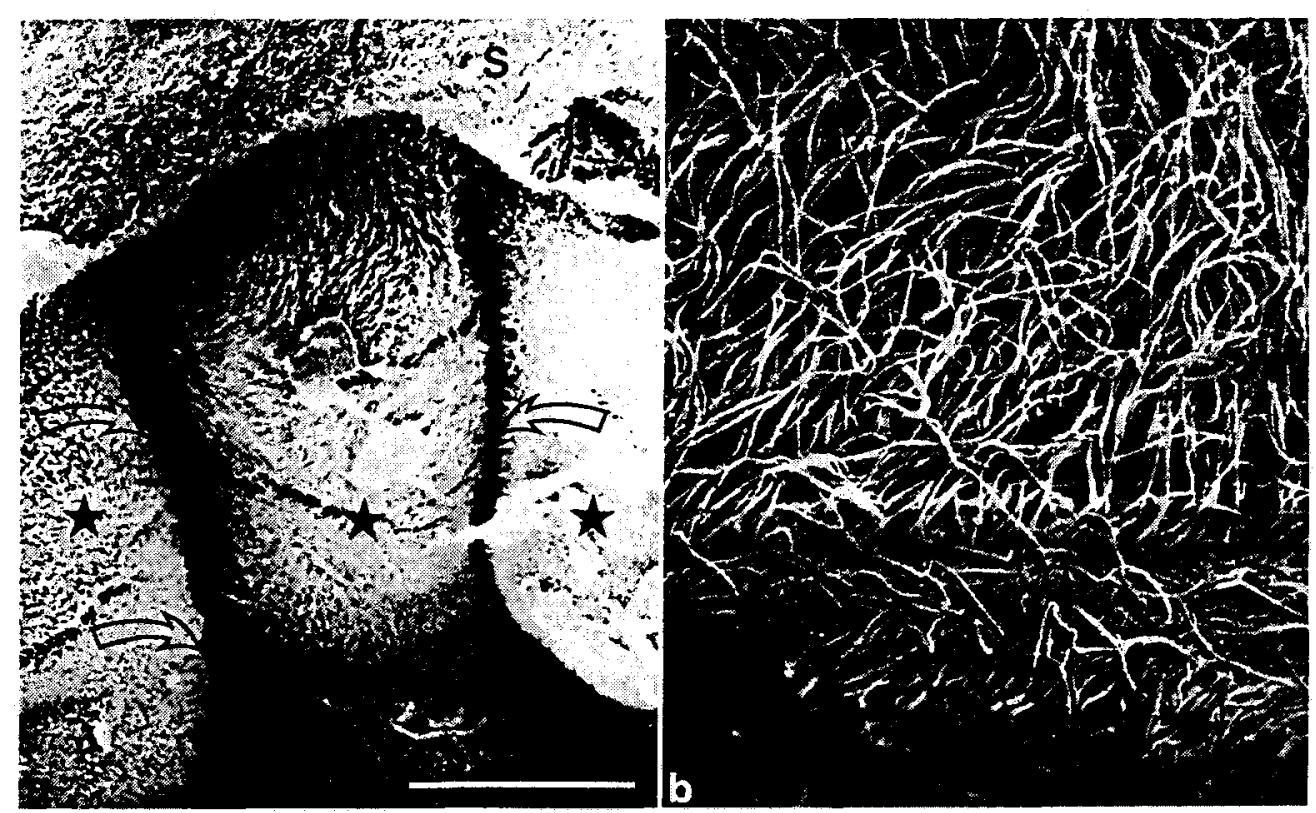

Fig. 18. Leptoseris fragilis. a: View through the stomodaeum into the pharynx (compare with Figs 4a, 17b). b: Close-up of the flagellar cover of the pharynx. Abbreviations: $s=$ border of the stomodaeum, asterisks $=$ central axial edges of sclerosepta, arrows $=$ access into the gastric ducts. Scale bars: 


\section{Pores in the oral epithelia}

Near the top of the crests of the sclerosepta, the oral epithelia are perforated by microscopic pores. Through the pores $(1-2 \mu \mathrm{m}$ in diameter $)$, the gastrovascular system communicates with the surrounding water (Fig. 19). Up to 20 pores are combined into functional units (interpore distance is $4-8 \mu \mathrm{m}$ ). The arrangement may be described, in analogy to laboratory equipment, as membrane filters.

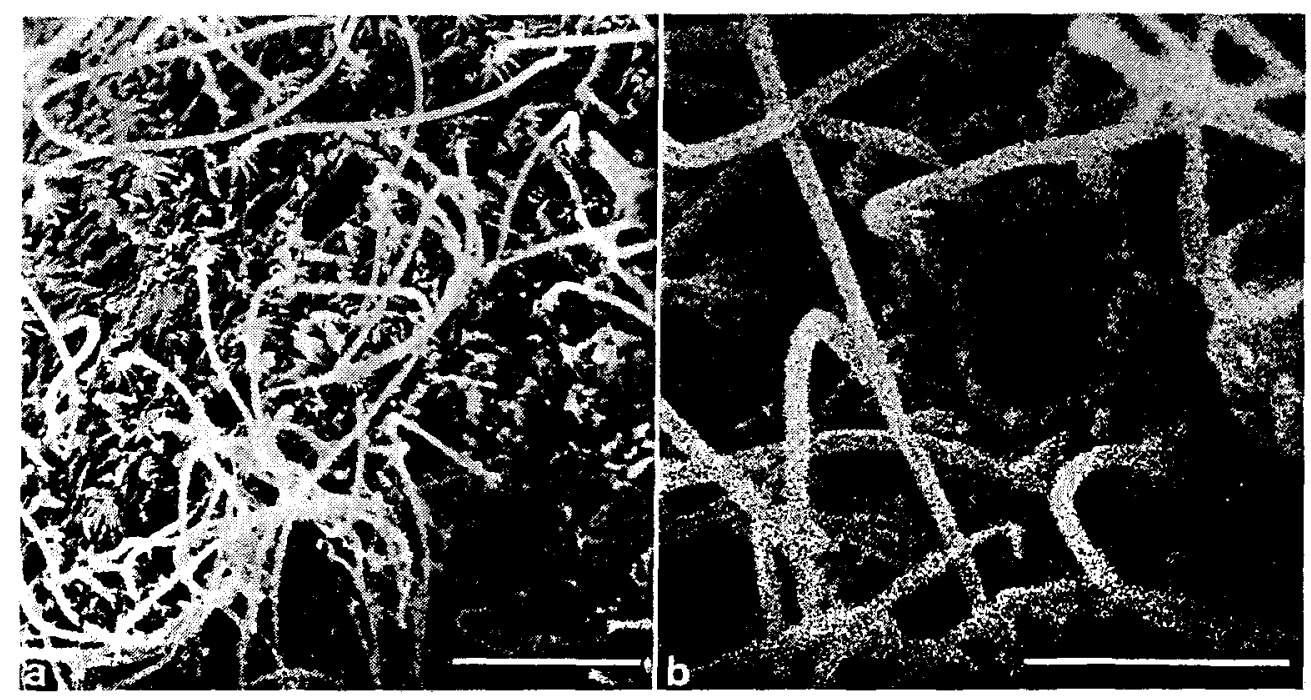

Fig. 19. Leptoseris fragilis. Microscopical pores in the oral epithelia near the crests of the sclerosepta (see insertion 6 in Fig. 8a). a: A group of pores. b: An individual pore. Scale bars: a: $6 \mu \mathrm{m}$; b: $3 \mu \mathrm{m}$

\section{DISCUSSION}

In this section, functional aspects of the epidermal pores are discussed with special reference to the retention of particles. The explanations, although based on the data presented here and on additional observations, are somewhat speculative and need further corroboration.

\section{Conventional organization and irrigation of the coelenteron}

The gastrovascular system (coelenteron) of corals serves several functions: (a) Its fluid constitutes a hydraulic skeleton and gives stability in cooperation with the lime skeleton, the mesogloea and the mesenteries; (b) The coelenteron is the space for the distribution and extracellular digestion of engulfed plankton or detritus; final digestion occurs in food vacuoles within gastrodermal cells; (c) The gastrovascular system is involved in respiration and in elimination of all kinds of waste products, furthermore in ion- and osmoregulation and in reproduction. The functions listed are all closely related to the fluid of the gastrovascular system and its renewal. 
The gastrovascular system of solitary anthozoans is assumed to be a blind sac. The single opening is mouth and anus equally. In tentacle bearing species the lumen of the tentacles communicates with the gastrovascular pockets. Due to flagellar activity, water and other contents are propelled within the system and also into and out of the mouth.

Larger openings occasionally observed in the tentacle tips of anthozoans most probably exist and work only temporarily: Due to the absence or reduction of the mesogloea in that particular region, the tissue layers may be mechanically perforated e.g. by increased pressure in the gastrovascular system caused by muscular activity. Those large openings are not related to the permanent microscopical pores in the external tissue layers of Leptoseris fragilis.

In small coral polyps in which horizontal transport over only short distances is required, it is conceivable that the aforementioned mechanism is sufficient. The fluid circulation powered by flagella is sometimes supported by muscular actions, i.e. the contraction of longitudinal muscles leads to an exchange of the contents of the coelenteron. Gladfelter (1983) discussed for Acropora cervicornis the circulation of fluids within canals $100 \mu \mathrm{m}$ in diameter, powered only by flagellae. In colonial species, however, the distances are shorter. In L. fragilis, transport has to be managed by means of gastral ducts less than $25 \mu \mathrm{m}$ in diameter and several centimeters in length. These dimensions make the operation of the conventional irrigation system in $L$. fragilis doubtful.

\section{The modified irrigation system of Leptoseris fragilis}

The flagella which densely cover the body surface of $L$. fragilis (Figs 10c, 18a, b), transport water and particles either towards the stomodaeum or in the opposite direction. The accessory structures surrounding the basal parts of the flagella (Fig. 10c, d) may have sensory functions that control the transport of useful/useless particles. For the discoidal genus Fungia and other coral species, a mechanism controlling the selection between useful und useless particles has been described (Yonge, 1930; Abe, 1938; Schuhmacher, 1979). In addition, flagellar activity inhibits the formation of unstirred layers on the body surface which would impede diffusion in general and also the absorption of dissolved organic compounds or the supply of inorganic nutrients to the zooxanthellae. The oral epidermis is well equipped with microvilli (Figs 10c, 18), facilitating the absorption of dissolved nutrients. $L$. fragilis is able to absorb and accumulate DOM (Schlichter, in preparation). Swelling of the polyparium, due to excess fluid filling the gastrovascular system which may cause slipping of particles from the surface, could not be observed. The external transport of particles in $L$. fragilis takes place along the grooves formed by adjacent sclerosepta (Figs $5 b, 8 b, 11 a, 16 a)$. On reaching the slope of the oral crater, the particles are transported in an upward direction onto the peristome, then downward into the stomodaeum. The upward transport could be a mechanism to fractionate the particles according to size, mass or electrostatic charge (Solow \& Gallager, 1990), in consequence of which only adequate particles would be ingested. Electronmicrographs give the impression that particles are not coated with mucous during transport along the surface. However, the possibility that mucous was eliminated during histological preparation may not be excluded. However, compared with the numerous mucous cells in the oral epidermis of Fungia klunzingeri (Döderlein), mucous cells in $L$. fragilis are scarce. Particles are ingested into the stomodaeum and are then moved into the pharynx. The 
particles are transported either directly by flagellar activity and/or by an inwardly directed stream of water. The water flow within the coelenteron is generated by (a) a "flagellar engine" located in the pharynx (Fig. 18), (b) the flagellar lining of the gastrovascular system (Fig. 14), and/or at least temporarily by (c) a lowering and elevation of the oral epithelia by muscles (see below). The ingested particles arrive at the pharynx where they are distributed directly into the gastrovascular pockets and ducts (Figs 17, 18). Minute particles appear to be glued to the columellar flagellae (Fig. 20). This

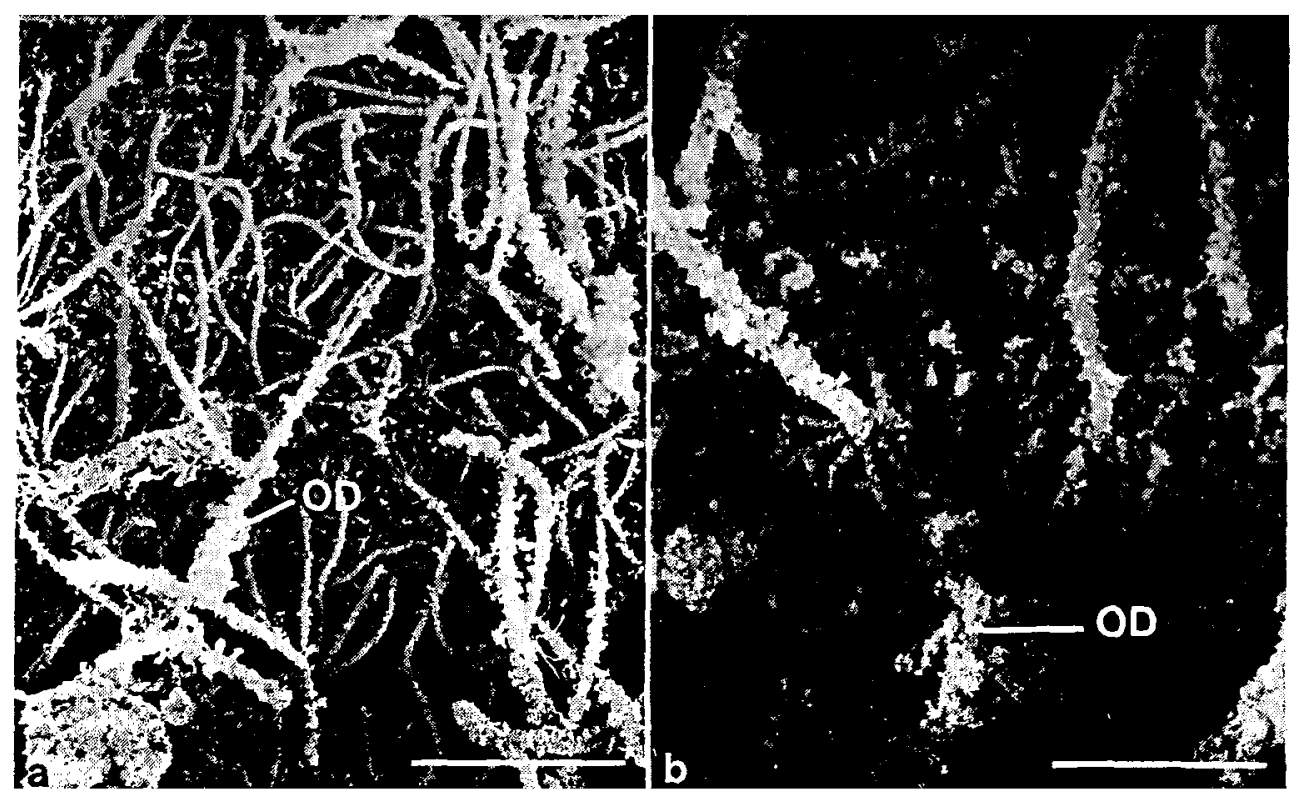

Fig. 20a, b: Surface view of the aboral gastrodermis coating the columella (compare with Fig. 10c). Abbreviation: $O D=$ organic debris. Scale bars: a: $13.6 \mu \mathrm{m} ; \mathrm{b}: 3.8 \mu \mathrm{m}$

contrasts with the particle transport on the external body surface. In the central regions of the corallite, the gastrovascular pockets communicate through perforations of the sclerosepta (Fig. 4b). The arrangement resembles a system of sieves of different mesh size which may allow the fractionation of particles in different categories: Larger particles are retained in the central regions, thus avoiding blocking of the ducts leading to the periphery. The diameter of the expanded gastric ducts ranges between 20 and $50 \mu \mathrm{m}$, and the length of the flagella lining the gastrovascular system averages 15 to $20 \mu \mathrm{m}$. At the periphery of the corallite the perforations of the sclerosepta disappear and the transport within the gastric ducts has theoretically to work to and fro, according to the conventional irrigation concept.

The lumen of the gastric ducts is confined by the lateral lamellae of the sclerosepta. The number of gastric ducts per scleroseptum declines from the centre towards the periphery (Fig. 5a). The open sides of the gastric ducts opposite the lamella are bordered by mesenteries. The mesenteries can probably close the canals temporarily (Fig. 16a). Closing of the gastric ducts and changes in their diameter - which is important for their 
function - may be caused by differences in water pressure pressing the mesenteries against the open sides of the ducts. The zip-like arrangement of the lamellae of adjacent sclerosepta may facilitate closing. Forces influencing the water pressure in the coelenteron are due to flagellar and muscular activity. The flagellar mechanism has already been discussed (see above). Contraction of the mesenterial retractor muscles would lead to volume reduction of the gastral pockets, which would be the first step in the irrigation of the gastrovascular system (see Figs $8 a, 16 a, b$ ). The original position could be reestablished hydraulically by filling the gastrovascular system again with water due to flagellar activity. Tissue retraction caused experimentally by light stress was often so strong that the sharp denticulated crests of the sclerosepta penetrated the oral epithelia. Studies in the future will show which of the two irrigation mechanisms mentioned is powerful enough to produce the waterflow through the pores.

The efficiency of particle capture and of retention of useful particles, as well as the efficiency of assimilation are of importance in the nutrition of filter feeders (Rubenstein \& Koehl, 1977; Solow \& Gallager, 1990). No data are available on the efficiency of assimilation; however, some information exists on the efficiency of particle capture and retention.

The gastrovascular system of solitary anthozoans is assumed to end blindly which complicates the transport of water and particles back and forth in narrow tubes of considerable length. $L$. fragilis may have solved the problem of efficient irrigation and suspension filter feeding in the following way: Particle capture is optimized by the platelike shape and the dense cover with flagella of the external body surface (Fig. 10c, d). The gastral cavity is not a blind but a flow-through system. The nutrient-containing water current enters $L$. fragilis through the stomodaeum and leaves the gastrovascular system not only through the mouth but also through epidermal pores (Fig. 19). The "lips" of the pores suggest that water streams only in one direction (Fig. 19b). The diameter of the pores is small enough to keep back picoplankton which does not have to be necessarily coated with mucous. Irrigation is powered by a pressure difference across the pore units. The pressure difference may be caused by the "pharyngeal flagellar engine" (Fig. 18) and flagellae coating the gastric ducts (Fig. 14). This unidirectional water flow leads to an accumulation of particles in the gastric ducts. As mentioned above, the irrigation could also be achieved by muscle actions (Figs $8 \mathrm{a}, \mathrm{b}, 16 \mathrm{~b}$ ): Contraction of the mesenterial retractor muscles would produce a water current, and provided the stomodaeum remains closed, the water would be pressed through the pores and suspended particles would be retained and concentrated. The continuous unidirectional water current through the gastrovascular system would also improve other functions of the coelenteron listed above.

Stated simply, the gastrovascular system of $L$. fragilis works like the filtration system of poriferans but in reverse with respect to the diameter of in- and outlets: In L. fragilis, water - free of suspended particles - leaves the body through microscopical pores of the oral epithelia.

The transport of wastes from the gastric ducts out through the mouth could be managed by flagellar activity or by the lowering and lifting mechanism. If the stomodaeum remains open during contraction of the mesenterial retractor muscles, indigestible material could be rejected through the mouth. This mechanism may work if the ducts are not set at a fixed size and the epithelia coating the gastric ducts are flexible 
and only partially attached to the corallite. The final deposition of undigestible material within the lowest gastric ducts could be another alternative to eliminate waste products, for the ducts lose their nutritive function in any case due to vertical growth of the skeleton (or in connection with carbonate deposition). The epidermal pores may also have nontrophic functions, e.g. the release of water more rapidly from the coelenteron during stress situations (e.g. fish grazing).

One aim of this study was to elucidate trophic adaptations in $L$. fragilis which may be responsible for the extraordinary bathymetric distribution of this zooxanthellate coral species. Energy calculations based on in situ measurements of respiration and photosynthesis indicate that in the northern part of the Gulf of Aqaba (Red Sea) the phototrophic input is not high enough to compensate the energetic requirements of host and symbionts during 6 to 8 months of the year (Fricke et al, 1987, 1992). The observations and morphological studies described here show how the capture and the retention of particles may be supported in a scleractinian coral species lacking tentacles. Due to the ability to extract even microscopical POM, the heterotrophic contribution to the nutrition of both host and symbionts appears to be optimized. Heterotrophy of the zooxanthellae themselves was proved by Steen (1986). Another strategy to endure periods of insufficient autotrophic supply would be to reduce metabolism or to use stored reserves, e.g. stored lipids which are of particular metabolic importance in corals. In zooxanthellate cnidarians it has been clearly shown that the cytosymbiotic algae are involved substantially in the synthesis of lipids of the host (Patton et al., 1977; Schlichter \& Kremer, 1985; Spencer Davis, 1991).

The occurrence of zooxanthellae in L. fragilis, growing on the border of the photic zone, should therefore be discussed under this synergistic point of view: During months of high solar elevation the zooxanthellae contribute to the, synthesis of lipid reserves of the host. Thus, the algae have an essential metabolic function which may explain the extreme efforts of the host to support photosynthesis by unique photoadaptations. $L$. fragilis could also successively utilize organic material accumulated within the gastric ducts during periods of high POM supply in the habitat. L. fragilis lives successfully with respect to energy supply in a habitat which favours neither phototrophic nor heterotrophic feeding habits. Solar irradiation in the habitat is low and of particular spectral composition. The habitat is far from the shallow, more productive zones, thus the supply with, for example, net plankton is considerably reduced (Johannes et al., 1970). Microbial biomass and detritus are abundant also in deeper reef areas (Marshal et al, 1975; Lewis, 1977; Mitskevich \& Kriss, 1982; Moriarty et al., 1985). Linley \& Koop (1986) argued that even pelagic bacteria are a potential major food resource for benthic filter feeders.

$L$. fragilis displays structural and physiological adaptations which compensate the barren trophic conditions of the habitat. Adaptations enabling photosynthesis were discussed in detail (Fricke et al., 1987, 1991; Schlichter et al., 1985, 1987, 1988; Schlichter \& Fricke, 1990, 1991). The present study indicates adaptations supporting POM feeding. $L$. fragilis successfully competes with other motile or sessile invertebrates in catching POM. In a speculative sense, the ability of $L$. fragilis to capture and keep back suspended particles of a diameter of 1 to $2 \mu \mathrm{m}$ could be the "secret" of gaining sufficient energy heterotrophically. The ability of scleractinians to retain suspended particles was already shown, for example by Lewis (1976). The flowthrough system of $L$. fragilis operates faster and more efficiently than blind gastrovascular systems. To my knowledge a similar 
system has not yet been described for corals. The reduction of catching surfaces in $L$. fragilis, i.e. the absence of tentacles, seems to be balanced by the ability to utilize particles which are extracted in the gastric ducts. The capture of larger plankton which makes tentacles and nematocysts necessary (the synthesis of both needs energy) seems to be of less importance for L. fragilis; the nematocysts might have a predominantly protective function.

The growth forms of scleractinian corals in general are discussed in terms of ecophysiological or anatomical adaptations to particular environmental conditions. The plate-like organization of $L$. fragilis is a means to kill two birds with one stone: (a) The zooxanthellae can - without shading each other - be optimally exposed to low irradiation; (b) the plain surface, densely covered with flagellae, operates as a trap collecting suspended particles not caught by the tentacles or by the nematocysts. Due to the perforated gastrovascular cavity the particles can efficiently be accumulated within the gastric ducts.

Acknowledgements. This study was supported by the Deutsche Forschungsgemeinschaft (Schl. 115/ 7-1 and Fr. 369/7-1). I would like to express my gratitude to Professor H. W. Fricke and the crew of the research submersible GEO for considerable help and encouragement. I thank M. Grosmann, $\mathrm{H}$. Krisch, H.-P. Bollhagen and J. Jacobi for skillful technical assistance. I am indebted to Drs E. Robson, M. LeTisier, G. Scheer and $H$. Schuhmacher for critical reading of the manuscript and for helpful comments and valuable suggestions. I, however, take responsibility for any errors.

\section{LITERATURE CITED}

Abe, N., 1938. Feeding behaviour and the nematocyst of Fungia and 15 other species of corals. Palao trop. biol. Stn Stud. 1 (3), 469-522.

Chevalier, J. P., 1987. Ordre des Scléractiniaires. In: Traité de zoologie. Ed. by P. P. Grassé. Masson, Paris, 498-539.

Fricke, H. W. \& Schuhmacher, H., 1983. The depth limits of Red Sea stony corals: an ecophysiological problem (a deep diving survey by submersible). - Mar. Ecol. Prog. Ser. 4, 163-194.

Fricke, H. W., Vareschi, E. \& Schlichter, D., 1987. Photoecology of the coral Leptoseris fragilis in the Red Sea twilight zone (an experimental study by submersible). - Oecologia 73, 271-381.

Fricke, H. W., Kaiser, P. \& Schlichter, D., 1992. Auto-heterotrophy in Leptoseris fragilis at the extreme limits of coral-algal photosynthesis. - Mar. Biol. (In press).

Gladfelter, E. H., 1983. Circulation of fluids in the gastrovascular system of the reef coral Acropora cervicornis. - Biol. Bull. mar. biol. Lab., Woods Hole 165, 619-636.

Hoeksema, B. W., 1989. Taxonomy, phylogeny and biogeography of mushroom corals (Scleractinia: Fungiidae). - Zool. Verh., Leiden 254, 1-295.

Johannes, R. E., Coles, S. L. \& Kuenzel, N. T., 1970. The role of zooplankton in the nutrition of some scleractinian corals. - Limnol. Oceanogr. 15, 579-586.

Le Tissier, M. D. A. A., 1990. The ultrastructure of the skeleton and skeletogenic tissues of the temperate coral Caryophyllia smithii. - J. mar. biol. Ass. U.K. 70, 295-310.

Lewis, J. B., 1976. Experimental tests of suspension feeding in Atlantic Reef Corals. - Mar. Biol. 36, $147-150$.

Lewis, J. B., 1977. Processes of organic production on coral reefs. - Biol. Rev. 52, 305-347.

Linley, E. A. S. \& Koop, K., 1986. Significance of pelagic bacteria as a trophic resource in a coral reef lagoon, One Tree Island, Great Barrier Reef. - Mar. Biol. 92, 457-464.

Marshall, N., Durbin, A. G., Gerber, R. \& Telek, G., 1975. Observations on particulate and dissolved organic matter in coral reef areas. - Int. Revue ges. Hydrobiol. 60, 335-345.

Mitskevich, I. N. \& Kriss, A. E., 1982. Distribution of the number, biomass and production of microorganisms in the world ocean. - Int. Revue ges. Hydrobiol. 67, 433-458. 
Moriarty, D. J. W., Pollard, P. C. \& Hunt, W. G., 1985. Temporal and spatial variation in bacterial production in the water column over a coral reef. - Mar. Biol. 85, 285-292.

Patton, J. S., Abraham, S. \& Benson, A. A., 1977. Lipogenesis in the intact coral Pocillopora capitata and its isolated zooxanthellae: evidence for a light-driven carbon cycle between symbiont and host. - Mar. Biol. 44, 235-247.

Pilkington, J. B., 1969. The organization of skeletal tissues in the spines of Echinus esculentus. J. mar. biol. Ass. U.K, 49, 857-877.

Rubenstein, D. I. \& Koehl, M. A. R., 1977. The mechanisms of filter feeding: some theoretical considerations. - Am. Nat. 111, 981-994.

Schlichter, D. \& Kremer, B. P., 1985. Metabolic competence of endocytobiotic dinoflagellates (zooxanthellae) in the soft coral, Heteroxenia fuscescens. - Endocyt. Cell Res. 2, 71-82.

Schlichter, D., Weber, W. \& Fricke, H. W., 1985. A chromatophore system in the hermatypic, deepwater coral Leptoseris fragilis (Anthozoa: Hexacorallia). - Mar. Biol. 89, 143-147.

Schlichter, D., Fricke, H. W. \& Weber, W., 1986. Light harvesting by wavelength transformation in a symbiotic coral of the Red Sea twilight zone. - Mar. Biol. 91, 403-407.

Schlichter, D., Fricke, H. W. \& Weber, W., 1988. Evidence for PAR-enhancement by reflection, scattering, and fluorescence in the symbiotic deep water coral Leptoseris fragilis (PAR = Photosynthetically Active Radiation). - Endocyt. Cell Res. 5, 83-94.

Schlichter, D. \& Fricke, H. W., 1990. Coral host improves photosynthesis of endosymbiotic algae. Naturwissenschaften 77, 447-450.

Schlichter, D. \& Fricke, H. W, 1991. Mechanisms of amplification of photosynthetically active radiation in the symbiotic deepwater coral Leptoseris fragilis - Hydrobiologia 216/217, 389-394.

Schuhmacher, H., 1979. Experimentelle Untersuchungen zur Anpassung von Fungiiden (Scleractinia, Fungiidae) an unterschiedliche Sedimentation- und Bodenverhältnisse. - Int. Revue ges. Hydrobiol. 2, 207-243.

Sebens, K. P., 1987. Feeding mechanisms of coelenterates. In: Animal energetics. Ed. by T. J. Pandian \& F. J. Vernberg. Acad. Press, San Diego, 1, 58-60.

Solow, A. R. \& Gallager, S. M., 1990. Analysis of capture efficiency in suspension feeding: application of nonparametric binary regression. - Mar. Biol. 107, 341-344.

Spencer Davies, P., 1991. Effect of daylight variations on the energy budgets of shallow-water corals. - Mar. Biol. 108, 137-144.

Spurr, R. A., 1969. A low-viscosity epoxy embedding medium for electron microscopy. - J. ultrastruct. Res. 26, 31-43.

Steen, R. G., 1986. Evidence for heterotrophy by zooxanthellae in symbiosis with Aiptasia pulchella. - Biol. Bull. mar. biol. Lab., Woods Hole 170, 267-278.

Yonge, C. M., 1930. Studies on the physiology of corals: I. Feeding mechanisms and food. - Scient. Rep. Gt Barrier Reef Exped. 1, 13-57. 